\title{
Assessment of Wear Properties under Dry Sliding Conditions on AISI 301LN Austenitic Stainless Steel by Plasma Nitriding Process
}

\author{
Divyasri. ${ }^{1}$, Ch.Phani Rama Krishna ${ }^{2}$, Pradeep Jayappa ${ }^{3}$, G.Keerthi Reddy ${ }^{4}$, V.Vinay Kumar ${ }^{2}$, B.Shankarachary ${ }^{5}$, \\ M.Surya ${ }^{6}$, Ram Subbiah $^{5^{*}}$ \\ ${ }^{1}$ UG Student, CVR College of Engineering, Hyderabad 501510, India \\ ${ }^{2}$ Department of Basic sciences \& Humanities, Gokaraju Rangaraju Institute of Engineering and Technology, Hyderabad 500090, India \\ ${ }^{3}$ Chemical Engineering, Bule Hora University, Ethiopia, Africa \\ ${ }^{4}$ PG Student, Design for Manufacturing, Gokaraju Rangaraju Institute of Engineering and Technology, Hyderabad 500090, India \\ ${ }^{5}$ Faculty, Mechanical Engineering, Gokaraju Rangaraju Institute of Engineering and Technology, Hyderabad 500090, India \\ ${ }^{6}$ UG Student, Design for Manufacturing, Gokaraju Rangaraju Institute of Engineering and Technology, Hyderabad 500090, India
}

\begin{abstract}
In industry, mechanical components must operate under conditions conditions such as variable load, speed, temperature and various chemical environments. Materials are selected depending on their application. They are selected for commercial availability, cost and properties such as strength, hardness etc. Many engineering errors are due to fatigue, corrosion and poor wear resistance occurring on its surface. This causes cracks in the surface that shortens the service life of the material. Also, the surfaces of materials are exposed to strong thermal, chemical and shock loads. Chosen for this research work, AISI 301LN materials have low surface hardness and poor wear properties, which can limit their applications were components mate each other. AISI 301LN stainless steel was treated with plasma nitriding at a low temperature of about $650^{\circ} \mathrm{C}$. It was observed that a mixture of ferrites and gradually nitrogenous matter accumulates in the following layers namely iron nitride. Further nitriding was carried out to $20 \mathrm{hrs}, 40 \mathrm{hrs}$, $60 \mathrm{hrs}$ and the specimen were named as PL1, PL2 and PL3 respectively. It was observed that Cr-N layer were formed on the outer surface. Wear tests were carried out on a tribological wear test machine to study the wear behavior. A comparison is made between treated and untreated specimens. The microstructures are investigated with scanning electron microscope.
\end{abstract}

\section{Introduction}

Austenitic stainless steel is widely used due to its resistance to corrosion, but some industrial applications require increased wear characteristics and tendency to sensitization [1-3]. These steels offer many advantages such as excellent cryogenic properties, corrosion protection and biocompatibility. Thus, these steels find wide applications like chemical Industry, ocean technology, food processing sectors, biomedicine, petrochemical industries etc. When they are alloyed with nitrogen, austenitic stainless steels have a more stable austenitic structure, better mechanical properties and better wear resistance. A variety of surface hardening methods are available, and the best surface modification method is selected to improve performance [4-6].

The research and development continues in stainless steel for the generation of new ideas to enhance mechanical properties. In the 1980's, the enhanced properties of austenitic stainless steel has became developed widespread. Thereby, the application of this material is limited due to poor wear [7-10]. Various surface hardening processes are available to improve tribological wear characteristics, but some processes are high cost. The alternate applies to conventional gas, plasma and salt bath nitriding. Among the different surface hardening methods available, nitriding offers the advantage of high surface stability [11-14]. Surface hardening process are been used to enhance the aspect of wear and hardness. In addition, thermo chemical low temperature nitriding is a method of improving the performance of austenitic stainless steels without affecting corrosive properties of the alloy [15-19]. Due to the formation of supersaturated solution of nitrogen in austenite, commonly referred to as expanded austenite that provides hardening, improved tribological properties, corrosion resistance respectively. The success of these materials is, they are produced relatively cheap and provide mechanical properties from moderate strength to adequate ductility [20-25].

* Corresponding author: author@e-mail.org 


\section{Experimental Details}

\subsection{Material Composition}

Chosen for this research work, AISI 301LN Stainless steel were finalized. The material composition is as follows Carbon $0.03 \%$, Manganese $1.99 \%$, silicon $0.9 \%$, Phosphorus $0.06 \%$, Sulphur $0.015 \%$, Chromium $16.5 \%$, Nickel $6.0 \%$, Nitrogen $0.11 \%$ and remaining Iron. The pin specimens were sliced to $12 \mathrm{~mm}$ diameter and 40 $\mathrm{mm}$ length. The dimensions of the disc are $150 \mathrm{~mm}$ diameter and thickness of $10 \mathrm{~mm}$.

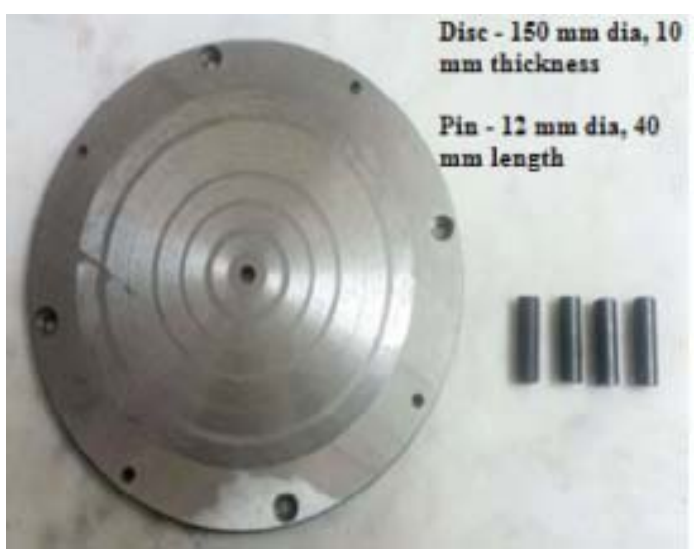

Fig. 1. AISI 301LN Specimens

\subsection{Treatments done on the Material}

In a vacuum, high voltage electric energy is been turned out to plasma, were nitrogen ions are accelerated into the work piece. Due to ion bombardment, work piece gets heated and generates active nitrogen. The samples were treated to $20 \mathrm{hrs}, 40 \mathrm{hrs}, 60 \mathrm{hrs}$. Plasma nitriding provides better case depth and uniform surface finish. Based on the process parameters and the material composition, a diffusion layer is formed with nitrogen deposited up to $0.8 \mathrm{~mm}$ on the surface. A compound zone is formed on the surface with micron range thickness. The hardness is changed by diffusing nitrogen in the solid solution, while the hardness increases in the form of nitride. Due to this diffusion towards the surface, fine, coherent precipitates are formed. The precipitate exists in both grain boundaries and within the lattice structure. These iron nitrides and fine precipitates, increases the hardness of the material. As a result nitrogen is transferred to the workpiece, $\mathrm{Cr}-\mathrm{N}$ layer penetrates inside by diffusion process. The plasma nitriding process provides wear, fatigue and corrosion resistant surfaces.

\subsection{Wear Test}



Fig. 2. Wear Test Tribometer

The samples were cleaned well by various grades of emery papers, polished well in disc polishing machine. Later the samples were etched using sulphuric acid for about 5 minutes and dried. With pin on disc tribometer as shown in Fig 2, the wear tests were carried out and the basic layout is shown in the Fig 3. With the disc of same grade treated to saturated limit, the disc were rotated at $1500 \mathrm{rpm}$, load of $20 \mathrm{~N}$ is applied at 3 minutes in sliding conditions without any lubricating agent. The treated samples were replaced one by one during wear test and the weight loss was monitored. The weight loss was determined, by measuring the specimen weight before and after applying the load. The wear characteristics and volume wear loss was tracked. Surface morphology was observed using SEM filtration. It was found that the volume loss of wear is to be $5.61 \mathrm{~mm}^{3}$ in the untreated sample. The Volume loss of PL1, PL2, PL3 was noted as on $4.41 \mathrm{~mm}^{3}, 3.42 \mathrm{~mm}^{3}$ and $2.01 \mathrm{~mm}^{3}$ respectively.

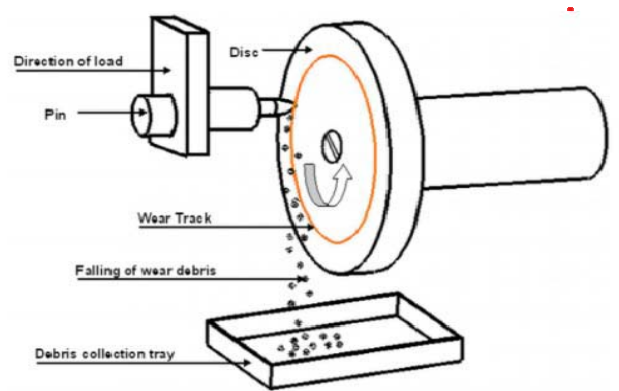

Fig. 3. Layout of Wear Test Process 


\section{Results and Discussion}

\subsection{Microstructure investigation}

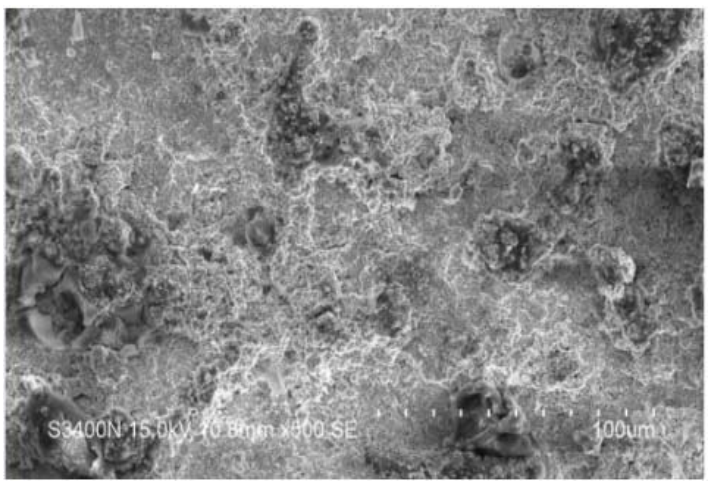

Fig. 4. Untreated AISI 301LN specimen SEM Image

It was observed that small cracks with micro-etching pits were noted. Material peels off on the surface of an untreated sample have been noted. It is due to low strength and low hardness of the material and the load applied during the wear test as shown in Fig 4.



Fig. 5. SEM Image of PL1 specimen

Nitrogen alloy makes a significant contribution to improved slip and corrosion impact of stainless steel as shown in Fig. 5. Since nitrogen alloy has higher solubility in solids, it reduces the hardening of the material. $\mathrm{Cr}-\mathrm{N}$ were formed in on the surface as expanded austenite layer. Due to the constant sedimentation of solid particles, the expanded austenite layer formed fine precipitation on austenite surface providing a lamellar austenite zone and $\mathrm{Cr}-\mathrm{N}$ as shown in Fig 5.

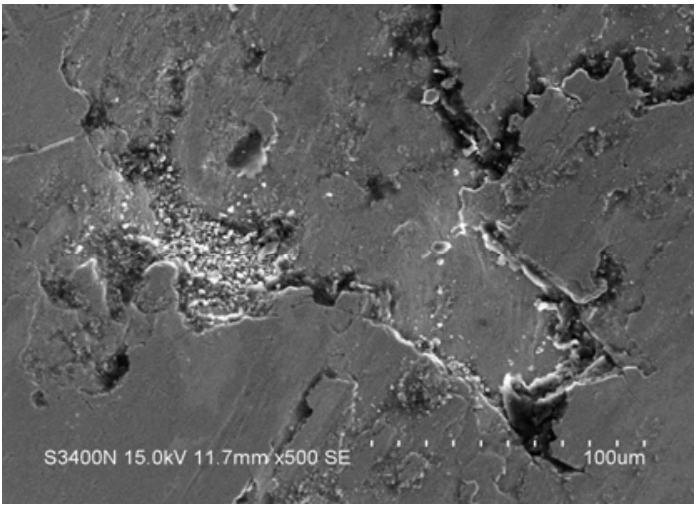

Fig. 6. SEM Image of PL2 specimen

It was observed that nitrogen as a solid solution has enhanced more hardening, and improved the grain size. Nitrogen is an austenitic stabilizer which reduces the nickel content for stabilization. Doping with nitrogen decreases the ability to form ferrite compounds. The material Peel turned out to be less, since there was increase in strength and hardness of the material which was compared against untreated specimen as shown in Fig 6.

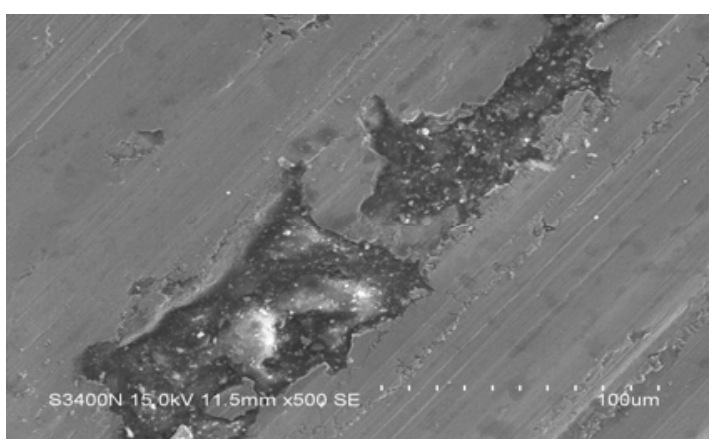

Fig. 7. SEM Image of PL3 specimen

The improvement in nitrogen content, in some temperature conditions, determines the precipitates of chromium nitirdes limits the austenite grains leads to decrease the resistance in crystalline corrosion. To eliminate this, nitridization is done to increase the surface hardness without affecting the property of material. The formation of chromium nitrides in austenitic stainless steel induces the chromium reduction leads the material protection towards corrosion as shown in Fig 7.

\section{Conclusions}

Very few researches have been made on AISI $301 \mathrm{LN}$ Stainless steel by plasma nitriding process. As a challenge of taking AISI 301LN material and problem for components exposed to high temperature applications like turbine blades were been subjected to the low temperature plasma diffusion process. The conclusions drawn from the work done are: When examining surface morphology, white areas during the wear test determines the austenite, formed as expanded austenite. On 
continuing the nitriding process, it has been expanded to the $\mathrm{Cr}-\mathrm{N}$; extremely nitrides of hard layer are composed of ferrite-nitride mixtures. Thick compound layers were identified in all plasma nitrided specimens which were noted in the diffusion zone. The volume loss of wear resistance of the untreated sample was $5.61 \mathrm{~mm}^{3}$ and the sample, nitrided with plasma for $60 \mathrm{hrs}$, turned out to be $2.01 \mathrm{~mm}^{3}$. The samples were undergone for hardness tests using Vickers hardness machine. It was noted that $322 \mathrm{H}_{\mathrm{v}}$ for an untreated specimen. And for plasma nitride specimen it was found as $711 \mathrm{H}_{\mathrm{v}}, 729 \mathrm{H}_{\mathrm{v}}, 761 \mathrm{H}_{\mathrm{v}}$ for PL1, PL2 and PL3 respectively. The formation of the $\mathrm{Fe}_{3} \mathrm{~N}, \mathrm{Fe}_{4} \mathrm{~N}$ and $\mathrm{CrN}$ on compound layer has improved the wear resistance of the material.

\section{References}

1. C. Arlos Mario Garzon, H. Thomas, J. Francisco Dosantos, Wear.J.E 259, 145 (2005).

2. H.J. Lee, S.H. Kim, H. Kim, C. Jang, Appl. Surf. Sci.J.E 388, 483 (2016)

3. F. Rouillard, F. Charton, G. Moine, Corrosion.J.E 67, 95001 (2011)

4. T. Furukawa, Y. Inagaki, M. Aritomi, Prog. Nucl. Energy.J. E 53, 1050 (2011)

5. T. Furukawa, F. Rouillard, Prog. Nucl. Energy.J.E 82, $136(2015)$

6. S.K. Bonagani, V. Bathula, V. Kain, Corrosion Science.J.E 131, 340 (2018).

7. M.Mamatha Gandhi, Animesh Bain, $P$ Rohith, R. Srilatha, Ram Subbiah, Structure and Topography Modifications of Treated AISI 316LN Stainless Steel Surfaces after Friction in Dry Sliding Contact by Case Hardening Process (EDP Sciences, Hyderabad, 2020)

8. K. Ramya Sree, G. Keerthi Reddy, K. Aishwarya, E. Nirmala Devi, Ram. Subbiah, New Insights of Wear Behavior Analysis on Low Temperature Treated AISI 253MA Stainless steel Material by Gas Nitriding Process (EDP Sciences, Hyderabad, 2020)

9. A Rohit Sai Krishna, B Vamshi Krishna, D Harshith, T Sashank, Ram Subbiah, Investigation of Mechanical Properties of AISI 316 Stainless Steel by Carbonitriding Process (EDP Sciences, Hyderabad, 2020)

10. Shivani Koppula, Aakula Rajkumar, Siram Hari Krishna, Reddi Sai Prudhvi, S. Aparna,Ram Subbiah, Improving the Mechanical Properties of AISI 2205 Duplex Stainless Steel by Cryogenic Treatment Process (EDP Sciences, Hyderabad, 2020)

11.Lakshmi Deepak Tadepalli, Ananda Mithra Gosala, Lokesh Kondamuru, Sai Chandra Bairi, A. Anitha Lakshmi, Ram Subbiah, Assessment of Properties on AISI430 Ferritic Stainless Steel by Nitriding process (EDP Sciences, Hyderabad, 2020)

12. Gandla Lakshmi Prasanna, G. Keerthi Reddy' Ram Subbiah, Evaluation of properties of AISI 431 Grade Stainless Steel by Vacuum Annealing Process (EDP Sciences, Hyderabad, 2020)
13. Gandla Lakshmi Prasanna, J Saranya, Ram Subbiah, Assessment of AISI 431Grade Stainless Steel properties by Vacuum Tempering Process (EDP Sciences, Hyderabad, 2020)

14. Manne Vamshi, J. Saranya, Ram Subbiah, Improvement of Characteristics of AISI 310 Grade Stainless Steel Material By Carburizing (EDP Sciences, Hyderabad, 2020)

15. ManneVamshi, AnimeshBain, M.Sreekanth, Ram Subbiah, Wear Characteristics of AISI 310 Grade Stainless Steel Material by Carbonitriding Process (EDP Sciences, Hyderabad, 2020)

16.Ram.Subbiah, Md.Rahel, A.Sravika R.Ambika, A.Srujana, E.Navya, Investigation on Microstructure and Mechanical Properties of P91 Alloy Steel Treated With Normalizing Process - A Review (Materials Today: Proceedings, Hyderabad, 2019)

17.A. Rohit Sai Krishna, B. Vamshi Krishna, T. Sashank, D. Harshith, Ram Subbiah, Influence and assessment of mechanical properties on treated P91 steel with normalizing processes (Materials Today: Proceedings, Hyderabad, 2020)

18.K. Manjith Srinivas, S. Bharath, P. N. V. Krishna Chaitanya, M. Pramod, Ram Subbiah, Improving tribological properties of P91 steels through carburizing process (Materials Today: Proceedings, Hyderabad, 2020)

19. B.Chaitanya kumar, P.Sri Charan, Kanishkar Jayakumar, D.Alankrutha, G.Sindhu, Ram Subbiah, Assessment of wear properties on low temperature molten salt bath nitriding on austenitic stainless steel (Materials Today: Proceedings, Hyderabad, 2020)

20.T.LakshmiDeepak,G.AnandaMithra, K. Lokesh, B. Sai Chandra, Ram Subbiah, Stability of expanded austenite by gas nitriding process on austenitic stainless steel material under low temperature conditions (Materials Today: Proceedings, Hyderabad, 2020)

21.Nirmala Devi, G.Chitra.S, Selvasekarapandian.S. Premalatha, M. Monisha, S. Saranya.J, Ionics.J.E 23, 2337 (2017)

22.Patel.S, Rana.R.S, Singh.S.K, Study on mechanical properties of environment friendly Aluminium Ewaste Composite with Fly ash and E-glass fiber (Materials Today: Proceedings, Hyderabad, 2017)

23.Prasad.K.S, Gupta.A.K, Singh.Y, Singh.S.K, Materi Eng and Perform.J.E 25, 5411 (2016)

24.Ganesh.R, Subbiah.R, Chandrasekaran.K, Dry Sliding Wear Behavior of Powder Metallurgy Aluminium Matrix Composite (Materials Today: Proceedings, Hyderabad, 2015)

25.Dhanalaxmi.B, Apparao Naidu.G, Anuradha, K, Adaptive PSO based association rule mining technique for software defect classification using $A N N$ (Procedia Computer Science, Hyderabad, 2015) 